\title{
Fine-scale genetic structure and relatedness in the eelgrass Zostera marina
}

\author{
Stephanie J. Kamel ${ }^{1, *}$, A. Randall Hughes ${ }^{2}$, Richard K. Grosberg ${ }^{1}$, \\ John J. Stachowicz ${ }^{1}$ \\ ${ }^{1}$ Center for Population Biology, Department of Evolution and Ecology, College of Biological Sciences, \\ University of California, 1 Shields Ave., Davis, California 95616, USA \\ ${ }^{2}$ Coastal and Marine Laboratory, Florida State University, 3618 Highway 98, St. Teresa, Florida 32358, USA
}

\begin{abstract}
The genetic composition of groups of individuals can significantly influence the productivity, resilience, and functioning of communities and ecosystems. For example, the relatedness of individuals within a group often dictates whether their interactions are competitive or cooperative. It is therefore necessary to characterize the genetic structure of populations at spatial scales relevant to these interactions and to determine the distribution of genetic diversity at those scales. Using microsatellite data, we assessed fine-scale population structure of Zostera marina, an important habitat-forming seagrass, within and between Bodega Harbor and Tomales Bay in northern California, USA. Despite the potential for long-range dispersal, we found significant population structure at all hierarchical scales (among bays, among sites, among tidal heights), corresponding to distances ranging from meters to tens of kilometers. The pattern of genetic differentiation that emerged at local scales differed between bays, with Tomales Bay being more structured even though the Euclidean distances among sites were similar in each bay. The relatedness of genets within a tidal height also differed among bays: in Bodega Harbor most genets occurred in proximity to unrelated individuals, whereas in Tomales Bay, genets were mixed with their close relatives, likely due to decreased dispersal. These contrasting kin structures, coupled with highly variable levels of clonal diversity, underscore the importance of examining variation at multiple scales, as this reveals genetic factors which might play an important role in many ecological processes.
\end{abstract}

KEY WORDS: Population structure $\cdot$ Relatedness $\cdot$ Dispersal $\cdot$ Genetic diversity $\cdot$ Zostera marina

\section{INTRODUCTION}

Evolutionary ecologists have long appreciated how the distribution of genetic variation within and among populations governs the nature and outcomes of many evolutionary responses (Slatkin 1987). More recently, it has become clear that many of the ecological processes underlying these evolutionary responses can, themselves, be strongly influenced by the local distribution of genetic diversity (reviewed in Whitham et al. 2006; Hughes et al. 2008). For instance, at the level of individuals, local genetic structure influences the likelihood of interactions among relatives, and thus opportunities for, and the costs and benefits of, cooperative (Hamilton 1964) or competitive (West et al. 2002) behaviors. Likewise, the proximity of relatives can influence the expression of a range of traits such as resource acquisition or reproductive allocation (Donohue 2004, Karban 2008, Arct et al. 2010).

The genotypic composition of groups of conspecific individuals, especially for ecological dominants or 
habitat-forming species, can also have profound effects at the population, community, and ecosystem levels, influencing total biomass, resilience from disturbance, invasion success, and the abundance and diversity of other species (Hughes \& Stachowicz 2004, 2009, Reusch et al. 2005, Crutsinger et al. 2006, Johnson et al. 2006, Vellend 2006, Whitham et al. 2006, Hughes et al. 2008). However, our understanding of the spatial scales at which genetic structure is partitioned in natural populations of these species is limited. More importantly, how this genetic variation is distributed at scales where it has been shown to affect ecological processes remains largely unexplored.

Among taxa with sessile or sedentary adults, including many plants and marine invertebrates, variation in the dispersal of gametes, seeds, and larvae can lead to substantial differences in the degree and scale over which populations exhibit genetic structure (e.g. Marko 2004, Hellberg 2009, Zhou \& Chen 2010). Within species, a complex pattern of genetic structure can arise from variation in the frequency, duration, and success of dispersal at each life stage, the incidence of local asexual propagation, the spatial distribution of suitable habitats (Ayre et al. 2009), variation in physical transport processes (Levin 2006), and the frequency of disturbance events (Reusch 2006). These complexities often make it difficult to predict the scales at which populations will exhibit genetic structure based on life-history characteristics alone (Veliz et al. 2006).

In the present paper we characterize the distribution of genetic variation at multiple spatial scales in the marine angiosperm Zostera marina (eelgrass), an important habitat-forming seagrass that is prevalent in bays and estuaries throughout the temperate northern hemisphere. $Z$. marina often forms monospecific meadows in soft sediments, enhancing coastal primary production, nutrient cycling, and sediment stabilization, and serving as an important nursery ground for many marine animals (Williams \& Heck 2001). Genetically distinct individuals grown in common gardens differ in important physiological and morphological traits related to these ecological functions (Hughes et al. 2009), and populations of eelgrass vary considerably in overall levels of genotypic diversity (Olsen et al. 2004, Becheler et al. 2010). Experimental manipulations show that this variation can have ecosystem-level consequences: increased genetic diversity enhances total biomass, as well as resistance and resilience to local environmental disturbance, and affects the abundance and diversity of epifaunal communities (Williams 2001, Hughes \& Stachowicz 2004, 2009, 2011, Reusch et al.
2005). However, it remains an open question whether naturally occurring populations of $Z$. marina exhibit genetic structure at the scale (e.g. meters or less) at which these ecological effects of genotypic diversity have been demonstrated (but see Ruggiero et al. 2005 for an example in the seagrass Cymodocea nodosa).

Several features of the life history and ecology of Zostera marina should promote population viscosity and yield genetic structure on spatial scales that could increase the likelihood of ecological interactions among close relatives. Like other seagrasses, $Z$. marina reproduces both sexually, through the production of seeds, and clonally, through the vegetative propagation of ramets via rhizome elongation. Movement of pollen and seeds appears limited to only a few meters from the flower, based on both direct observations and indirect measurements of gene flow using genetic markers (Orth et al. 1994, Ruckelshaus 1996). On the other hand, most population genetic studies reveal little regional population structure and only weak signatures of isolation by distance (IBD), suggesting that the realized dispersal of seeds could occur at much larger scales $(\sim 50 \mathrm{~km}$; see review by Procaccini et al. 2007). Seed-bearing shoots are commonly uprooted and have been found

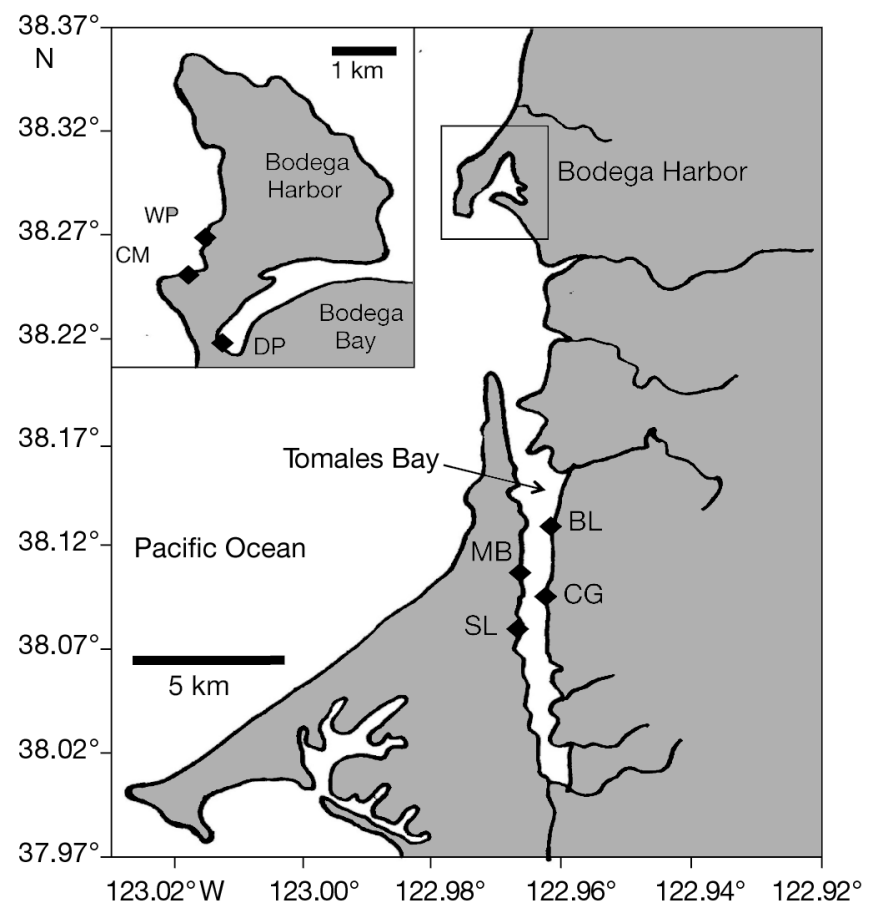

Fig. 1. Sampling sites in Tomales Bay and Bodega Harbor, northern California, USA. West Tomales: MB: Marshall Beach, SL: Sacramento Landing. East Tomales: BL: Blake's Landing, CG: Cypress Grove. Inset of Bodega Harbor: CM: Channel Marker, DP: Doran Park, WP: Westside Park 
drifting or washed ashore (Harwell \& Orth 2002), providing a potential dispersal mechanism over these larger spatial scales. In fact, Reusch (2002) reported finding individuals in the drift that were genetically distinct from those in the resident population and inferred that these shoots had likely traveled at least several kilometers.

Given the uncertainty regarding the realized dispersal of Zostera marina, it is difficult to predict the scale and magnitude of genetic structure in natural populations of this species. Yet, documenting this structure will be essential for judging the vitality and potential resilience of eelgrass beds in the face of anthropogenic change (e.g. Reusch et al. 2005). Here, we use microsatellite markers to characterize genetic structure in $Z$. marina over multiple spatial scales, ranging from meters to tens of kilometers. We then consider how the patterns of genetic structure which emerge at these different scales might influence individual and population-level traits and how these, in turn, can shape ecosystem processes.

\section{MATERIALS AND METHODS}

\section{Study area and sample collection}

We collected eelgrass samples from 7 sites across 3 regions in northern California, USA that differ in the distribution of eelgrass and the slope of the tidal gradient (Fig. 1): (1) Bodega Harbor (3 sites: Doran Park [DP], Channel Marker [CM], and Westside Park [WP]); (2) the west side of Tomales Bay (2 sites: Marshall Beach [MB] and Sacramento Landing [SL]); and (3) the east side of Tomales Bay (2 sites: Blake's Landing [BL] and Cypress Grove [CG]). Eelgrass in Bodega Harbor occurs primarily in a semi-continuous strip along each side of a steep, dredged channel. All 3 Bodega Harbor sites were located along this channel and exhibited a relatively steep transition $(<30 \mathrm{~m})$ from high intertidal (above mean lower low water [MLLW, designated as $0 \mathrm{~m}$ ]) to subtidal (0.5 to $1.0 \mathrm{~m}$ below MLLW) eelgrass. Along the western side of Tomales Bay, eelgrass typically occurs in discrete, shallow coves separated by rocky substrate. The slope at these sites also transitioned quickly (within $40 \mathrm{~m}$ ) from high intertidal to subtidal eelgrass. The eastern side of Tomales Bay, in contrast, is lined by an extensive, semi-continuous expanse of eelgrass with a very shallow gradient from high to low intertidal $(>100 \mathrm{~m})$ edges. Within the bays, sites were separated by $<5 \mathrm{~km}$, and between bays, sites were separated by up to $23 \mathrm{~km}$ (Fig. 1).
At 6 of the sites we randomly established four $1 \mathrm{~m}^{2}$ quadrats in continuous parts of the eelgrass bed at each of 3 tidal elevations with respect to MLLW: high intertidal, low intertidal, and subtidal. At one site (SL), we were only able to establish 3 quadrats in the high intertidal due to the low abundance of eelgrass at this tidal height. We collected tissue samples during summer 2001 (Bodega Bay and west Tomales) and 2003 (east Tomales) from 25 randomly selected shoots in each $1 \mathrm{~m}^{2}$ plot. Tissue samples were stored on ice for transport and then frozen at $-80^{\circ} \mathrm{C}$.

\section{DNA extraction, isolation, and microsatellite scoring}

We extracted genomic DNA using a modified cetyltrimethylammonium bromide (CTAB) protocol from Doyle \& Doyle (1987). We genotyped each sample at 5 microsatellite loci isolated from Zostera marina (European Molecular Biology Laboratory loci accession numbers: ZosmarCT-12_AJ249303, ZosmarCT-19_AJ249304, ZosmarCT-3_AJ009898, ZosmarGA-2_AJ009900, and ZosmarGA-3_AJ009901; hereafter called CT12, CT19, CT3, GA2, and GA3, respectively; Table $\mathrm{S} 1$ in the supplement at www.intres.com/articles/suppl/m447p127_supp.pdf).

We used $\sim 5 \mathrm{ng}$ of DNA to seed a $10 \mu \mathrm{l}$ PCR and amplified using a Perkin-Elmer PCR System 9700. Amplification conditions were as follows: 2 min denaturation at $94^{\circ} \mathrm{C}$, followed by 35 to 36 cycles of $30 \mathrm{~s}$ annealing (at 55 to $65^{\circ} \mathrm{C}$ ), $45 \mathrm{~s}$ extension at $72^{\circ} \mathrm{C}$, and 10 to $15 \mathrm{~s}$ denaturation at $94^{\circ} \mathrm{C}$, followed by a terminal extension step of $2 \mathrm{~min}$. Products were checked on $2 \%$ agarose gels before being run on polyacrylamide sequencing gels. PCR products were resolved by $6 \%$ polyacrylamide gel electrophoresis (PAGE), visualized by using silver nitrate staining (Promega Silver Sequence, catalog no. Q4132), and manually scored against a pUC/M13 sequence ladder.

\section{Data analysis}

To identify genetically unique individuals (i.e. to discriminate all clonal lineages [genets] and to assign each sampling unit [ramet] to its corresponding lineage), we used the methods described in ArnaudHaond et al. (2007a) and implemented in the program GENCLONE 2.0 (Arnaud-Haond \& Belkhir 2007). Briefly, we calculated $p_{\text {gen }}$, the probability of occurrence of a given 5-locus genotype, and used it to estimate $p_{\text {sex }}$, which is the probability that 2 repli- 
cates of a particular clonal lineage are actually derived from 2 separate sexual events. When $p_{\text {sex }}$ $<0.01$, then 2 identical genotypes are considered to belong to the same genet (Arnaud-Haond et al. 2007a). In addition, to assess whether similar, but not identical, genotypes actually belonged to the same genet, with the discrepancy potentially arising from somatic mutations or scoring errors, we applied the methods described in Arnaud-Haond \& Belkhir (2007) and Arnaud-Haond et al. (2007a, 2007b).

After excluding repeatedly sampled ramets and thereby restricting the data set to unique genets, we used GENEPOP 4.0 (Raymond \& Rousset 1995) to estimate expected heterozygosity $\left(H_{\mathrm{e}}\right)$ and to test for linkage disequilibrium (LD) and conformation to Hardy-Weinberg expectations (HWE). We calculated allelic richness (Ar) using FSTAT version 2.9.3.2 (Goudet 1995).

\section{Spatial genetic structure and population differentiation}

Using only unique genets, we characterized Zostera marina genetic structure at 4 spatial scales: (1) among bays, (2) among sites within bays, (3) among tidal heights within sites, and (4) within tidal heights. We did not include individual quadrats in these analyses of population structure because several quadrats were isoclonal, and so sampled shoots could not be considered as independent because they were all from the same genet. Rather, we grouped all the genets within a tidal height at a given site, resulting in 21 tidal height $\times$ site combinations (hereafter referred to as tidal height).

To partition genetic variance within and among spatial scales, we used a hierarchical analysis of molecular variance (AMOVA, implemented in the HIERFSTAT package in R version 2.12.0; Goudet 2005). To test for the influence of local hierarchical structure on overall patterns, we performed 2 additional AMOVAs: (1) within Bodega Harbor and (2) within Tomales Bay. We also used the Bayesian model-based clustering algorithm implemented by the program STRUCTURE version 2.2.3 (Pritchard et al. 2000) to detect cryptic population genetic structure and to assign individuals to inferred subpopulation clusters based on multilocus genotypes. We assessed the number of genetic clusters $(K)$ among our 7 sites for values of $K$ ranging from 1 to 10 using the admixture model with allelic frequencies correlated among populations and ignoring prior population information. We ran 10 Bayesian Markov chain
Monte Carlo (MCMC) searches of 1000000 steps with a 100000 step burn-in, and used the maximal values of $\Delta K$ based on the rate of change in the log probability of data between successive $K$ values (Evanno et al. 2005) to find the value of $K$ that best fit the observed distribution of multilocus genotypes.

To assess the degree of genetic structure among sites and among tidal heights, we determined all pairwise values of population differentiation by calculating Weir \& Cockerham's F-statistics $\left(F_{\mathrm{IS}}, F_{\mathrm{IT}}\right.$, $F_{\mathrm{ST}}$ ) using ARLEQUIN version 3.11, and tested for significance by 10000 permutations of the data (Excoffier et al. 2005). To characterize the relationship between inferred levels of gene flow and geographic distance between sites, we conducted Mantel tests for non-random associations between matrices of geographic and genetic distances using the program IBDWS (Jensen et al. 2005). The geographic distance (in $\mathrm{km}$ ) between sites was the shortest over-water path connecting those points. Significance of correlations in all Mantel tests was assessed with 10000 matrix randomizations.

\section{Genetic diversity and relatedness}

At the scale of both tidal height $(\mathrm{n}=21)$ and quadrat $(\mathrm{n}=83)$, we measured genotypic richness $(R)$ using $R=(G-1) /(N-1)$, where $G$ is the number of unique genotypes and $N$ is the total number of shoots analyzed. We also measured diversity using the Shannon index $\left(H^{\prime}\right)$ and evenness $\left(\mathrm{ED}^{*}\right)$ as a relative measure of clonal abundance. Genotypic richness, diversity, and evenness were calculated using GENCLONE 2.0 (Arnaud-Haond \& Belkhir 2007).

We determined the relatedness $(r)$ among genets using the program STORM (Frasier 2008). This method was chosen out of the many available approaches for calculating relatedness because it is unbiased, it is never undefined, and it consistently performs well in a variety of situations, and often outperforms all other estimators (see Frasier 2008 and references therein). This coefficient is closely related to the coefficient of coancestry $\left(F_{i j}\right)$ between 2 individuals $i$ and $j$, which is often used in spatial autocorrelation analyses and provides the same information: under Hardy-Weinberg genotypic proportions with diploids, $r_{i j}=2 F_{i j}$ (Vekemans \& Hardy 2004). In the absence of inbreeding, the expected value of $r$ for (1) unrelated individuals, (2) parent-offspring or fullsibs, and (3) half-sibs is 0, 0.5, and 0.25, respectively (Queller \& Goodnight 1989). Where applicable, results are presented as mean $\pm \mathrm{SD}$. 


\section{RESULTS}

From the 2075 shoots collected, we obtained complete genotypes for 1619 individuals at 5 microsatellite loci from 3 tidal heights at 7 different sites $(\mathrm{n}=21)$. All loci were polymorphic, ranging from 7 alleles at Locus CT19 to 13 alleles at Locus CT3 with a mean of 9.8 alleles locus ${ }^{-1}$ (Table S2 in the supplement at www.int-res.com/articles/suppl/m447p127 _supp.pdf). Analysis of variation at these loci using GENCLONE 2.0 revealed 322 unique genets. We found shared multilocus genotypes between quadrats within sites and between tidal heights within sites, but none among sites or among bays.

Across tidal heights, $F_{\text {IS }}$ values did not differ significantly from zero after sequential Bonferroni correction (Table 1). All 3 of the tidal heights with a significant departure from HWE were from Tomales Bay. Of the 220 tests for LD, 47 $(21.4 \%)$ were significant. Pairs of loci were nonrandomly associated in a maximum of 7 of the 21 locations (mean: 4, range: 1 to 7 ). However, there was no significant LD for any pair of loci (total of 10 pairs) across all locations, consistent with non-random mating rather than physical linkage of the loci (Becheler et al. 2010). We detected a small but significant homozygote deficit at the CT3 and GA2 loci and an excess of homozygotes at Locus GA3, and the exact test of Raymond \& Rousset (1995) indicated a global departure from HWE $\left(F_{\mathrm{IS}}=0.06, \mathrm{p}<0.01\right.$; Table $\mathrm{S} 2$ in the supplement).

Table 1. Zostera marina. Parameters relating to clonal structure for each tidal location $-N$ : number of genotyped shoots, $G$ : number of genets, $R$ : clonal richness, $H^{\prime}$ : Shannon index of clonal diversity, ED*: Simpson's evenness index. Parameters relating to genetic structure $-H_{\mathrm{e}}$ : expected heterozygosity, $H_{\mathrm{o}}$ : observed heterozygosity. $A$ : mean number of alleles per loci, Ar: allelic richness, standardized to a sample size of 5 genets for the tidal heights and 36 genets for the sites, and $F_{\text {IS }}$ : inbreeding coefficient. HI: high intertidal, LI: low intertidal, and S: subtidal. Bold indicates significant heterozygote excess at $\mathrm{p}<0.05$, before sequential Bonferroni correction. See Fig. 1 for site abbreviations

\begin{tabular}{|c|c|c|c|c|c|c|c|c|c|c|c|c|}
\hline Bay & Site & Tide & $N$ & $G$ & $R$ & $H^{\prime}$ & $\mathrm{ED}^{*}$ & $A$ & $H_{\mathrm{o}}$ & $H_{\mathrm{e}}$ & $\mathrm{Ar}$ & $F_{\mathrm{IS}}$ \\
\hline Tomales & MB & $\mathrm{HI}$ & 76 & 19 & 0.24 & 2.28 & 0.81 & 3.20 & 0.547 & 0.491 & 2.61 & -0.119 \\
\hline \multirow[t]{7}{*}{ West } & & LI & 77 & 18 & 0.22 & 2.33 & 0.86 & 3.80 & 0.622 & 0.538 & 2.89 & -0.162 \\
\hline & & $\mathrm{S}$ & 74 & 16 & 0.21 & 2.18 & 0.83 & 4.60 & 0.689 & 0.588 & 3.17 & -0.178 \\
\hline & & Total & & & & & & 5.20 & 0.618 & 0.556 & 4.95 & -0.112 \\
\hline & SL & $\mathrm{HI}$ & 59 & 5 & 0.07 & 1.35 & 0.88 & 3.40 & 0.520 & 0.569 & 3.40 & 0.096 \\
\hline & & LI & 74 & 15 & 0.19 & 2.23 & 0.87 & 4.20 & 0.587 & 0.543 & 2.94 & -0.085 \\
\hline & & $\mathrm{S}$ & 78 & 17 & 0.21 & 2.21 & 0.83 & 4.00 & 0.600 & 0.586 & 3.12 & -0.024 \\
\hline & & Total & & & & & & 4.60 & 0.584 & 0.581 & 4.59 & -0.006 \\
\hline Tomales & $\mathrm{BL}$ & $\mathrm{HI}$ & 80 & 13 & 0.15 & 2.02 & 0.87 & 3.40 & 0.462 & 0.452 & 2.68 & -0.021 \\
\hline \multirow[t]{7}{*}{ East } & & LI & 80 & 22 & 0.27 & 2.40 & 0.80 & 3.40 & 0.618 & 0.584 & 3.06 & -0.059 \\
\hline & & $\mathrm{S}$ & 80 & 39 & 0.48 & 3.25 & 0.86 & 4.20 & 0.667 & 0.604 & 3.12 & -0.106 \\
\hline & & Total & & & & & & 5.60 & 0.616 & 0.622 & 4.98 & 0.010 \\
\hline & $\mathrm{CG}$ & $\mathrm{HI}$ & 80 & 20 & 0.24 & 2.44 & 0.86 & 4.80 & 0.510 & 0.535 & 3.00 & 0.049 \\
\hline & & $\mathrm{LI}$ & 80 & 17 & 0.20 & 2.37 & 0.89 & 4.80 & 0.624 & 0.592 & 3.39 & -0.055 \\
\hline & & $\mathrm{S}$ & 80 & 9 & 0.10 & 1.81 & 0.88 & 3.40 & 0.520 & 0.509 & 2.80 & -0.022 \\
\hline & & Total & & & & & & 6.60 & 0.553 & 0.570 & 6.25 & 0.031 \\
\hline Bodega & $\mathrm{CM}$ & $\mathrm{HI}$ & 74 & 10 & 0.12 & 1.86 & 0.88 & 3.60 & 0.660 & 0.618 & 3.26 & -0.072 \\
\hline \multirow[t]{10}{*}{ Harbor } & & LI & 78 & 22 & 0.27 & 2.89 & 0.89 & 4.40 & 0.572 & 0.557 & 2.94 & -0.030 \\
\hline & & $\mathrm{S}$ & 79 & 9 & 0.10 & 1.82 & 0.89 & 3.80 & 0.689 & 0.668 & 3.39 & -0.033 \\
\hline & & Total & & & & & & 4.80 & 0.610 & 0.593 & 4.72 & -0.029 \\
\hline & DP & $\mathrm{HI}$ & 80 & 14 & 0.16 & 2.30 & 0.93 & 4.00 & 0.600 & 0.591 & 3.09 & -0.016 \\
\hline & & LI & 78 & 16 & 0.19 & 2.22 & 0.86 & 5.00 & 0.713 & 0.673 & 3.71 & -0.060 \\
\hline & & $\mathrm{S}$ & 79 & 6 & 0.06 & 1.66 & 0.95 & 3.00 & 0.533 & 0.576 & 2.83 & 0.080 \\
\hline & & Total & & & & & & 5.40 & 0.639 & 0.639 & 5.40 & 0.000 \\
\hline & WP & $\mathrm{HI}$ & 79 & 26 & 0.32 & 2.83 & 0.91 & 4.80 & 0.646 & 0.611 & 3.24 & -0.060 \\
\hline & & LI & 74 & 10 & 0.12 & 2.58 & 0.92 & 4.00 & 0.640 & 0.623 & 3.18 & -0.029 \\
\hline & & $\mathrm{S}$ & 78 & 13 & 0.16 & 2.02 & 0.85 & 3.80 & 0.600 & 0.634 & 3.20 & 0.055 \\
\hline Total & & & & & & & & 6.00 & 0.633 & 0.635 & 5.49 & 0.004 \\
\hline
\end{tabular}




\section{Spatial genetic structure and popula- tion differentiation}

The global AMOVA revealed significant structure at all levels (Table 2). Almost all the genetic variation $(85.3 \%)$ occurred among genets within tidal heights. The greatest proportion of spatial genetic variation was due to differences among bays (9.3\%) and among tidal heights within sites $(5.1 \%)$. This pattern was similar for both within-bay AMOVAs, with most of the variation occurring within tidal heights. There was slightly more hierarchical structure in Tomales Bay, with differences among sites, as well as among tidal heights within sites, explaining a significant proportion of the variation (Table 2c).

Bayesian clustering analyses revealed similar patterns of population structuring. STRUCTURE identified 2 significant clusters of microsatellite genotypes that corresponded to Tomales Bay and Bodega Harbor populations. Although the variance in the posterior probability of the estimate of the number of clusters in the microsatellite data was high for values of $K \geq 4$, the $\Delta K$ method of Evanno et al. (2005) showed a strong mode at $K=2$ (Fig. S1 in the supplement at www.int-res.com/articles/suppl/ m447p127_supp.pdf).

Analyses of pairwise genetic distance $\left(F_{\mathrm{ST}}\right)$ revealed significant genetic differentiation among the 7 sites (Table 3 ). All pairwise $F_{\mathrm{ST}}$ values differed significantly from zero except for one case which corresponded to a pair of sites within Bodega Harbor (CM and DP). This pattern was also evident at finer scales: $F_{\mathrm{ST}}$ values were all sig- nificantly different between pairs of tidal heights from different bays; however, within Tomales Bay, 56 of $66(84.8 \%) \quad F_{\mathrm{ST}}$ values were significantly different from zero $(\mathrm{p}<0.05)$, whereas only 15 out of $36(41.7 \%)$ pairwise values significantly differed within Bodega Harbor (Table S3 in the supplement at www.int-res.com/articles/suppl/m447p127 supp.pdf).

The Mantel test showed a significant, positive correlation between geographic distance and $F_{\mathrm{ST}}\left(\mathrm{R}^{2}=\right.$ $0.67, \mathrm{p}<0.01$ ). Some of this is clearly driven by the sampling scheme which results in 2 groups of points representing the inter- versus intra-bay distances among locations (Fig. 2). However, there was a significant correlation when only considering either pairs between bays $\left(R^{2}=0.26, p=0.04\right)$ or pairs within bays $\left(R^{2}=0.56, p=0.02\right)$, suggesting that distance may be an important factor acting at both local and regional scales.

Table 3. Zostera marina. Matrix of pairwise differences among the 7 sites. Above the diagonal, genetic distances $\left(F_{\mathrm{ST}}\right)$ are calculated following Weir \& Cockerham (1984); below the diagonal, geographic distances are expressed in km. $F_{\mathrm{ST}}$ values in italics are not significant, values in bold are significant at $\mathrm{p}<0.05$, and all other $F_{\mathrm{ST}}$ values are significant at $\mathrm{p}<0.0001$. See Fig. 1 for site abbreviations

\begin{tabular}{|llccccccc|}
\hline Bay & & MB & SL & BL & CG & CM & DP & WP \\
\hline Tomales & MB & - & 0.059 & 0.053 & 0.022 & 0.204 & 0.149 & 0.164 \\
& SL & 1.6 & - & 0.046 & 0.033 & 0.141 & 0.108 & 0.106 \\
& BL & 3.6 & 5.0 & - & 0.035 & 0.095 & 0.058 & 0.081 \\
& CG & 1.4 & 1.8 & 3.6 & - & 0.164 & 0.119 & 0.130 \\
Bodega & CM & 20.3 & 21.9 & 17.4 & 20.8 & - & 0.008 & $\mathbf{0 . 0 1 2}$ \\
& DP & 20.8 & 22.4 & 17.9 & 21.3 & 0.7 & 0.9 & $\mathbf{0 . 0 1 0}$ \\
& WP & 20.8 & 22.4 & 17.9 & 21.3 & 0.9 & - \\
\hline
\end{tabular}




\section{Genetic diversity and relatedness}

Heterozygosity and allelic richness were uniformly high within sites (mean: $0.61 \pm 0.03$ and 5.20 \pm 0.57 , respectively; $\mathrm{n}=7$ ) and tidal heights (mean: $0.6 \pm$ 0.07 and $3.10 \pm 0.26$, respectively; $\mathrm{n}=21$; Table 1 ) $R$ varied considerably among tidal heights, ranging from 0.06 to 0.48 (corresponding to 6 and 39 genotypes, respectively), with a mean of 0.19 (16 genotypes; Table 1). Overall, mean richness and $H^{\prime}$ did not differ significantly between Tomales Bay and Bodega Harbor (richness: 0.22 and 0.17, respectively; $t$-test: $t=1.16, \mathrm{p}=0.26 ; H^{\prime}: 2.24$ and 2.24 , respectively; $t$-test: $t=0.016, \mathrm{p}=0.99$ ).

At the quadrat level, richness was also highly variable. When we grouped quadrats by tidal height, we found a significant interaction between the effects of bay and tidal height on genotypic richness, with higher richness in the intertidal than in the subtidal sites in Bodega (independent contrasts: $F=3.96, \mathrm{p}=$ 0.05), but not in east Tomales (independent contrasts: $F=1.35, \mathrm{p}=0.25)$. At the west Tomales sites, the trend was in the opposite direction, with genotypic diversity slightly higher in the subtidal than the intertidal (independent contrasts: $F=3.33, p=0.07$; Fig. 3).

The relatedness among genets within a given tidal height varied widely, from $r=-0.03$ at BL low intertidal to $r=0.42$ at MB high intertidal (Table 4). Overall, group relatedness differed significantly between the bays: genets within Bodega Harbor tidal heights had a mean relatedness of 0.09 (range: -0.02 to 0.17 ) and genets within Tomales Bay tidal heights had a

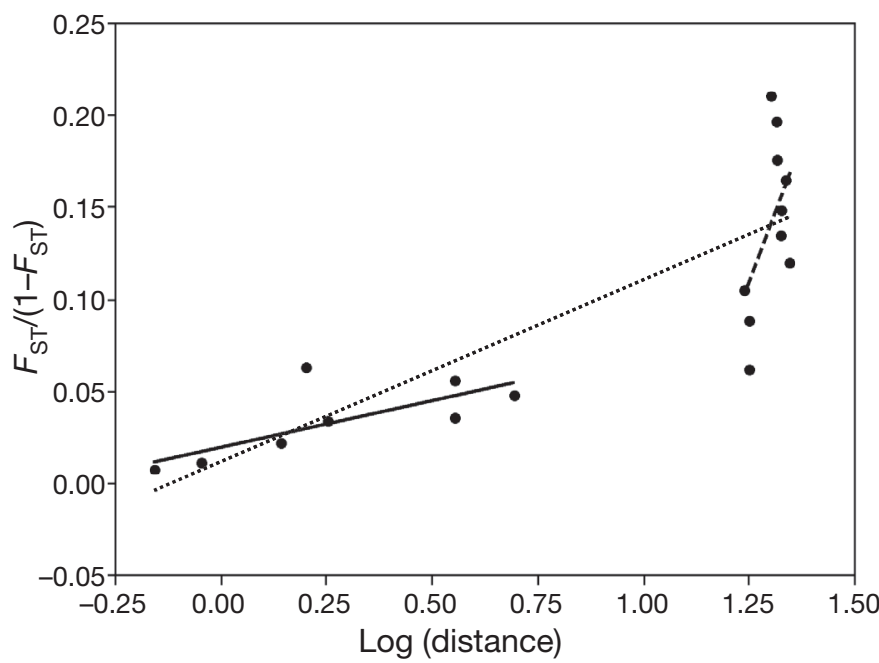

Fig. 2. Zostera marina. Isolation by distance: regression of pairs within a location (local scale; solid line), among locations (regional scale; dashed line), and across both distance classes (dotted line) mean relatedness of 0.21 (range: -0.03 to 0.42 ; Mann-Whitney test: $U=28.0, \mathrm{p}=0.04$ ).

At the quadrat level, relatedness among genets also differed significantly between the bays ( $t$-test: $t=1.998, \mathrm{p}=0.05)$, with relatedness values being significantly higher in Tomales Bay $(r=0.50 \pm 0.34, \mathrm{n}=$ 47 quadrats $)$ than in Bodega Harbor $(r=0.33 \pm 0.39$, $\mathrm{n}=36$ quadrats). When quadrat $r$ values were combined across tidal heights, mean values were higher but a similar pattern emerged (Table 4). Relatedness values were much higher when calculated on a per quadrat basis because some quadrats were isoclonal and thus had a relatedness of 1 .

\section{DISCUSSION}

Our work was motivated by the need to understand the extent to which genetic variation in natural populations of an ecologically important species is parti-

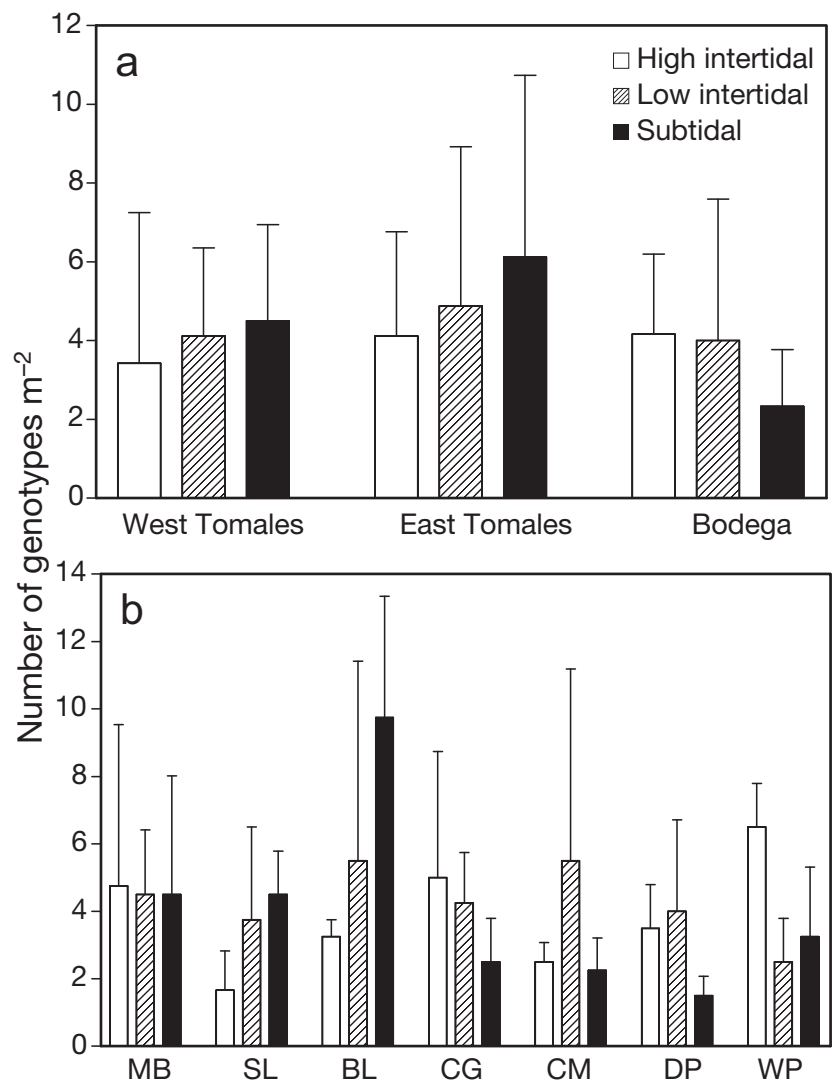

Fig. 3. Zostera marina. (a) Effects of region and tidal height on within-quadrat genotypic diversity; diversity is significantly higher in the intertidal than the subtidal in Bodega Harbor (independent contrasts: $p=0.05$ ). (b) Effects of site and tidal height on within-quadrat genotypic diversity by sampling location. Data are mean + SD. See Fig. 1 for site abbreviations 
Table 4. Zostera marina. Within-group relatedness values for each tidal height. Relatedness $(r)$ was calculated using (1) all genets within a given tidal height and (2) among genets within a quadrat and then averaged across the tidal height. HI: high intertidal, LI: low intertidal, and S: subtidal. See Fig. 1 for site abbreviations

\begin{tabular}{|c|c|c|c|c|}
\hline Bay & Site & $\begin{array}{c}\text { Tidal } \\
\text { height }\end{array}$ & $\begin{array}{l}r \text { using } \\
\text { all genets } \\
\quad(1)\end{array}$ & $\begin{array}{c}r \text { averaged } \\
\text { across quadrats } \\
(2)\end{array}$ \\
\hline \multirow{6}{*}{$\begin{array}{l}\text { Tomales } \\
\text { West }\end{array}$} & \multirow[t]{3}{*}{$\mathrm{MB}$} & HI & 0.42 & 0.76 \\
\hline & & LI & 0.39 & 0.55 \\
\hline & & $\mathrm{S}$ & 0.11 & 0.50 \\
\hline & \multirow[t]{3}{*}{ SL } & HI & 0.06 & 0.59 \\
\hline & & LI & 0.24 & 0.61 \\
\hline & & $\mathrm{S}$ & 0.22 & 0.34 \\
\hline \multirow{6}{*}{$\begin{array}{l}\text { Tomales } \\
\text { East }\end{array}$} & \multirow[t]{3}{*}{$\mathrm{BL}$} & HI & 0.18 & 0.52 \\
\hline & & LI & -0.03 & 0.49 \\
\hline & & $\mathrm{S}$ & 0.03 & 0.16 \\
\hline & \multirow[t]{3}{*}{$\mathrm{CG}$} & HI & 0.24 & 0.42 \\
\hline & & LI & 0.21 & 0.40 \\
\hline & & $\mathrm{S}$ & 0.41 & 0.70 \\
\hline \multirow{9}{*}{$\begin{array}{l}\text { Bodega } \\
\text { Harbor }\end{array}$} & \multirow[t]{3}{*}{$\mathrm{CM}$} & HI & 0.12 & 0.39 \\
\hline & & LI & 0.16 & 0.48 \\
\hline & & $\mathrm{S}$ & -0.02 & 0.37 \\
\hline & \multirow[t]{3}{*}{$\mathrm{DP}$} & $\mathrm{HI}$ & 0.15 & 0.11 \\
\hline & & LI & 0.01 & 0.03 \\
\hline & & $\mathrm{S}$ & 0.17 & 0.61 \\
\hline & \multirow[t]{3}{*}{ WP } & $\mathrm{HI}$ & 0.16 & 0.29 \\
\hline & & LI & 0.07 & 0.38 \\
\hline & & $\mathrm{S}$ & 0.04 & 0.44 \\
\hline
\end{tabular}

tioned across multiple scales, particularly in the context of ecological interactions among conspecific individuals and their emergent effects on ecosystem processes. The present study revealed significant genetic structure in Zostera marina among bays, but also at much finer scales that correspond to the scales at which diversity-driven ecological effects occur. Fine-scale genotypic diversity ranged from 1 to 15 genets $\mathrm{m}^{-2}$ (mean: 4 genets $\mathrm{m}^{-2}$ ). Furthermore, analyses of relatedness among genets indicate that at some tidal heights, genets are most likely to occur near unrelated individuals, whereas at other heights, genets intermingle mostly with their close relatives, suggesting much more restricted dispersal of seeds and pollen.

Genetic differentiation between populations in Tomales Bay and Bodega Harbor explained the greatest amount of variation in structure, suggesting that genetic exchange in this region is restricted at distances $\geq 25 \mathrm{~km}$. The analysis of IBD also showed increasing genetic dissimilarity with increasing distance at local scales (1 to $5 \mathrm{~km}$ ). Previous studies showed that the strength of IBD in Z. marina substantially varies among regions (Olsen et al. 2004, Procaccini et al. 2007, Becheler et al. 2010), although in many European populations, as well as those in the eastern USA (Campanella et al. 2010), there is little evidence for IBD at distances less than 150 to $250 \mathrm{~km}$.

This discrepancy between the scale of genetic structure in central California versus other populations of eelgrass may partly reflect the highly fragmented distribution of suitable eelgrass habitat in California. Eelgrass is restricted to protected bays and estuaries, which are presently relatively sparse along the California coast. The predominant currents run north to south along this coast, and the nearest extensive habitat for eelgrass north of Bodega Harbor is $>350 \mathrm{~km}$ away in Humboldt Bay (although there is a small population $160 \mathrm{~km}$ north in Fort Bragg). To the south, it is $50 \mathrm{~km}$ from suitable habitat in Tomales Bay to the nearest site in Drake's Estero, around the southern tip of Point Reyes. In more continuous eelgrass habitats in Europe, there appears to be increased gene flow among distant populations. For example, some populations in the southwest Baltic and Wadden Sea are not significantly differentiated at distances $\sim 50 \mathrm{~km}$ (Reusch 2002). Rare, longdistance dispersal has been documented in seagrasses (van Dijk et al. 2009), and the fact that Zostera marina has moderately buoyant leaves and spathes, durable seeds (Orth et al. 1994), and a monoecious mating system makes gradual, steppingstone dispersal a viable possibility (Olsen et al. 2004). In cases where no such stepping-stones are present in Europe, such as between the central Baltic Sea and the Mediterranean Sea, populations are isolated and show regional structure on a scale (10 to $100 \mathrm{~km})$ similar to that observed in our study.

Genetic structure at smaller spatial scales was more pronounced in Tomales Bay than in Bodega Harbor, even though the Euclidean distances among sites were on the same order of magnitude in both bays $(\leq 5 \mathrm{~km})$. In comparisons of pairwise $F_{\mathrm{ST}}$ among tidal heights within bays, there were many fewer locations that were significantly genetically different from one another in Bodega Harbor compared to those in Tomales Bay. In separate hierarchical analyses of variance for each bay, there was significant structuring among sites and among tidal heights within sites in Tomales Bay, but this was weak or absent in Bodega Harbor (Table 2).

Given that the 7 sites were relatively similar distances apart and that tidal heights were all separated by 15 to $30 \mathrm{~m}$, seeds and pollen do not have greater distances to travel in Tomales Bay, and therefore 
Euclidean distance cannot explain the disparity between bays in the magnitude of population structure. Thus, it appears that, at least within sites, the effect of distance per se might be less important than other biotic or abiotic features of the environment. This disconnect between genetic and geographic distances at fine scales has been reported in numerous marine taxa, including Zostera marina (Becheler et al. 2010) and other seagrasses (Arnaud-Haond et al. 2007b), as well as invertebrates (Edmands et al. 1996) and fish (Hogan et al. 2010).

In our study, local bathymetric or oceanographic features that influence the transport of pollen and seeds may account for at least some of the observed differences in patterns of genetic structure between Tomales Bay and Bodega Harbor sites. For example, the central dredged channel in Bodega Harbor effectively drains the entire bay during many low tides, and because all the sites are located along this channel, this may facilitate dispersal among sites and tidal heights, resulting in fewer significant pairwise $F_{\mathrm{ST}}$ values among tidal heights. In Tomales Bay, the sites are located along either side of the central section of the bay (ca. 10 to $12 \mathrm{~km}$ from the mouth) and here, a small tidal excursion infrequently mixes the inner portions of the estuary with coastal waters from June to October, causing increased residence times, and providing little means for pollen or seeds to spread widely (Kimbro et al. 2009), and resulting in higher levels of differentiation among tidal heights.

It is also possible that gene flow is not limited by dispersal but rather by factors such as low seed germination due to intraspecific competition (ArnaudHaond et al. 2007b) or local adaptation to spatially varying selection (Hellberg 2009). Using allozymes and expressed sequence tag (EST)-derived microsatellites, several studies have found patterns consistent with adaptation across a tidal gradient in Zostera marina (Ruckelshaus 1998, Oetjen \& Reusch 2007), although tidal zones were separated by 0.5 to $4 \mathrm{~km}$, distances much greater than those in the present study (10 to $30 \mathrm{~m}$ ). However, local adaptation across a narrow intertidal gradient has been reported for other marine macrophytes (Hays 2007) and so remains an intriguing possibility here.

Overall, measures of genetic diversity, such as clonal richness and heterozygosity, did not differ significantly between bays, but the distribution of this diversity varied markedly. Within a given tidal height at a particular site, we found from 5 to 39 unique genotypes; indeed, within a single $1 \mathrm{~m}^{2}$ quadrat, the number of genets ranged from 1 to 15 . This is in striking contrast to spatial patterns of clonal diversity in some European populations, where eelgrass beds can contain one or several large genets (e.g. Åland Island, Finland: clone length $\approx 160 \mathrm{~m}$, Reusch et al. 2000; Baltic Sea: clone length $>50 \mathrm{~m}$, Olsen et al. 2004), and clones are often aggregated over distances $>3 \mathrm{~m}$ (Hammerli \& Reusch 2003, Billingham et al. 2007). This disparity may reflect the fact that we primarily sampled intertidal to shallow subtidal $(<1 \mathrm{~m}$ deep at low tide) beds, whereas the beds sampled in other studies of $Z$. marina genetic diversity were primarily subtidal. Indeed, the subtidal sites that we sampled in our study, notably those in Bodega Harbor, consistently exhibited lower diversity than our intertidal sites (Fig. 3). This corresponds to a marked decline in flowering frequency with depth observed in Bodega Harbor, a pattern less evident in Tomales Bay (Hughes 2006). Other possible mechanisms contributing to declining diversity with depth include decreasing disturbance and pollination efficiency with depth; however, these should operate equally in both bays, yet the depth gradient in diversity is only evident in Bodega. We also reanalyzed the site-level genotypic richness data from populations in Europe and North America (Olsen et al. 2004), and found a strong negative correlation between depth and richness $\left(\mathrm{r}^{2}=0.13, \mathrm{p}=0.01\right)$, suggesting that this pattern may be widespread, whatever the underlying mechanisms. Interestingly, even within single $1 \mathrm{~m}^{2}$ quadrats, we were often able to recapture allelic richness values similar to or greater than those reported for other Z. marina beds (Olsen et al. 2004, Becheler et al. 2010, Campanella et al. 2010). This is consistent with the global comparison of Olsen et al. (2004) where the Bodega Channel population had the highest allelic richness among populations sampled from North America and Europe.

Our results have implications for understanding the ecological consequences of genetic diversity in natural settings (Vellend 2006, Hughes et al. 2008). While a growing number of studies have manipulated the diversity of genotypes in field or greenhouse experiments (reviewed in Hughes et al. 2008), few studies consider the natural distribution of genetic variation in these species in the design or interpretation of those experiments (e.g. Tack \& Roslin 2011). However, it is critical to establish that the spatial scales over which diversity varies correspond to the spatial scales over which diversitydependent ecological processes operate. For $Z$. marina, we show that there is significant variation in clonal richness and genetic relatedness at the scales at which experiments revealing such diversity-dependent effects have been conducted. Our 
results highlight that even when locations are similar in overall genotypic richness and diversity, there can still be spatial genetic structure, as demonstrated by the differences in relatedness among genets in Bodega Harbor versus Tomales Bay, both among tidal heights and individual quadrats.

These differences in the incidence of interactions with non-self (versus clonemates) and with unrelated versus related conspecifics can have profound implications for a wide range of ecologically relevant traits. For example, behaviors that reduce competition among members of the same genet have been reported for several plant species: when in contact with genetically identical individuals, they develop fewer and shorter roots and have more uniform plant heights than when in contact with non-self conspecifics (Karban 2008, Biernaskie 2011). The implications of these sorts of interactions for understanding the effects of genotypic diversity on eelgrass resistance and resilience to disturbance (Hughes \& Stachowicz 2004, 2011, Reusch et al. 2005) are currently unknown. However, previous findings in other plant species provide enticing evidence that such interactions can alter the distribution of above- and belowground biomass as well as plant morphology, and thus may play a critical role in the link between genotypic diversity and ecosystem-level processes. These contrasting opportunities for kin interactions, coupled with highly variable levels of genotypic diversity, underscore the importance of examining genetic structure at ecologically relevant scales.

Acknowledgements. This study was supported by a grant from the National Science Foundation to J.J.S. and A.R.H. (OCE-06-23641) and to R.K.G. (OCE-09-09078). We thank A. Fish and T. DiMarco for assistance in the lab.

\section{LITERATURE CITED}

Arct A, Rutkowska J, Martyka R, Drobniak SM, Cichon M (2010) Kin recognition and adjustment of reproductive effort in zebra finches. Biol Lett 6:762-764

Arnaud-Haond S, Belkhir K (2007) GENCLONE: a computer program to analyse genotypic data, test for clonality and describe spatial clonal organization. Mol Ecol Notes $7: 15-17$

Arnaud-Haond S, Duarte CM, Alberto F, Serrao EA (2007a) Standardizing methods to address clonality in population studies. Mol Ecol 16:5115-5139

> Arnaud-Haond S, Migliaccio M, Diaz-Almela E, Teixeira S and others $(2007 \mathrm{~b})$ Vicariance patterns in the Mediterranean Sea: east-west cleavage and low dispersal in the endemic seagrass Posidonia oceanica. J Biogeogr 34:963-976
Ayre DJ, Minchinton TE, Perrin C (2009) Does life history predict past and current connectivity for rocky intertidal invertebrates across a marine biogeographic barrier? Mol Ecol 18:1887-1903

> Becheler R, Diekmann O, Hily C, Moalic Y, Arnaud-Haond S (2010) The concept of population in clonal organisms: mosaics of temporally colonized patches are forming highly diverse meadows of Zostera marina in Brittany. Mol Ecol 19:2394-2407

> Biernaskie JM (2011) Evidence for competition and cooperation among climbing plants. Proc R Soc Lond B 278:1989-1996

Billingham MR, Simoes T, Reusch TBH, Serrao EA (2007) Genetic sub-structure and intermediate optimal outcrossing distance in the marine angiosperm Zostera marina. Mar Biol 152:793-801

Campanella JJ, Bologna PA, Smalley JV, Rosenzweig EB, Smith SM (2010) Population structure of Zostera marina (eelgrass) on the Western Atlantic coast is characterized by poor connectivity and inbreeding. J Hered 101:61-70

Crutsinger GM, Collins MD, Fordyce JA, Gompert Z, Nice CC, Sanders NJ (2006) Plant genotypic diversity predicts community structure and governs an ecosystem process. Science 313:966-968

> Donohue K (2004) Density-dependent multilevel selection in the Great Lakes sea rocket. Ecology 85:180-191

Doyle JJ, Doyle JL (1987) A rapid DNA isolation procedure for small quantities of fresh leaf tissue. Phytochem Bull 19:11-15

$>$ Edmands S, Moberg PE, Burton RS (1996) Allozyme and mitochondrial DNA evidence of population subdivision in the purple sea urchin Strongylocentrotus purpuratus. Mar Biol 126:443-450

Evanno G, Regnaut S, Goudet J (2005) Detecting the number of clusters of individuals using the software STRUCTURE: a simulation study. Mol Ecol 14:2611-2620

> Excoffier L, Laval G, Schneider S (2005) Arlequin (version 3.0): an integrated software package for population genetics data analysis. Evol Bioinform Online 1:47-50

> Frasier TR (2008) STORM: software for testing hypotheses of relatedness and mating patterns. Mol Ecol Resour 8:1263-1266

Goudet J (1995) FSTAT (version 1.2): a computer program to calculate F-statistics. J Hered 86:485-486

> Goudet J (2005) HIERFSTAT, a package for R to compute and test hierarchical F-statistics. Mol Ecol Notes 5:184-186

$>$ Hamilton WD (1964) The genetical evolution of social behaviour. I. J Theor Biol 7:1-16

> Hammerli A, Reusch TBH (2003) Genetic neighbourhood of clone structures in eelgrass meadows quantified by spatial autocorrelation of microsatellite markers. Heredity 91:448-455

Harwell MC, Orth RJ (2002) Long-distance dispersal potential in a marine macrophyte. Ecology 83:3319-3330

> Hays CG (2007) Adaptive phenotypic differentiation across the intertidal gradient in the alga Silvetia compressa. Ecology 88:149-157

Hellberg ME (2009) Gene flow and isolation among populations of marine animals. Annu Rev Ecol Evol Syst 40:291-310

Hogan JD, Thiessen RJ, Heath DD (2010) Variability in connectivity indicated by chaotic genetic patchiness within and among populations of a marine fish. Mar Ecol Prog Ser 417:263-275 
Hughes AR (2006) The ecological consequences of genetic diversity in eelgrass (Zostera marina) $\mathrm{PhD}$ thesis, University of California, Davis

> Hughes AR, Stachowicz JJ (2004) Genetic diversity enhances the resistance of a seagrass ecosystem to disturbance. Proc Natl Acad Sci USA 101:8998-9002

> Hughes AR, Stachowicz JJ (2009) Ecological impacts of genotypic diversity in the clonal seagrass Zostera marina. Ecology 90:1412-1419

Hughes AR, Stachowicz JJ (2011) Seagrass genotypic diversity increases disturbance response via complementarity and dominance. J Ecol 99:445-453

> Hughes AR, Inouye BD, Johnson MTJ, Underwood N, Vellend M (2008) Ecological consequences of genetic diversity. Ecol Lett 11:609-623

Hughes AR, Stachowicz JJ, Williams SL (2009) Morphological and physiological variation among seagrass (Zostera marina) genotypes. Oecologia 159:725-733

Jensen JL, Bohonak AJ, Kelley ST (2005) Isolation by distance, web service. BMC Genet 6:13, doi:10.1186/14712156-6-13

> Johnson MTJ, Lajeunesse MJ, Agrawal AA (2006) Additive and interactive effects of plant genotypic diversity on arthropod communities and plant fitness. Ecol Lett 9:24-34

Karban R (2008) Plant behaviour and communication. Ecol Lett 11:727-739

> Kimbro DL, Largier J, Grosholz ED (2009) Coastal oceanographic processes influence the growth and size of a key estuarine species, the Olympia oyster. Limnol Oceanogr 54:1425-1437

Levin LA (2006) Recent progress in understanding larval dispersal: new directions and digressions. Integr Comp Biol 46:282-297

Marko PB (2004) 'What's larvae got to do with it?' Disparate patterns of post-glacial population structure in two benthic marine gastropods with identical dispersal potential. Mol Ecol 13:597-611

Oetjen K, Reusch TBH (2007) Genome scans detect consistent divergent selection among subtidal vs. intertidal populations of the marine angiosperm Zostera marina. Mol Ecol 16:5156-5167

Olsen JL, Stam WT, Coyer JA, Reusch TBH and others (2004) North Atlantic phylogeography and large-scale population differentiation of the seagrass Zostera marina L. Mol Ecol 13:1923-1941

Orth RJ, Luckenbach M, Moore KA (1994) Seed dispersal in a marine macrophyte: implications for colonization and restoration. Ecology 75:1927-1939

Pritchard JK, Stephens M, Donnelly P (2000) Inference of population structure using multilocus genotype data. Genetics 155:945-959

> Procaccini G, Olsen JL, Reusch TBH (2007) Contribution of genetics and genomics to seagrass biology and conservation. J Exp Mar Biol Ecol 350:234-259

Queller DC, Goodnight KF (1989) Estimating relatedness using genetic markers. Evolution 43:258-275

Raymond M, Rousset F (1995) GENEPOP (version 1.2) population genetics software for exact tests and ecumenicism. J Hered 86:248-249

Editorial responsibility: Peter Steinberg,

Sydney, New South Wales, Australia
Reusch TBH (2002) Microsatellites reveal high population connectivity in eelgrass (Zostera marina) in two contrasting coastal areas. Limnol Oceanogr 47:78-85

Reusch TBH (2006) Does disturbance enhance genotypic diversity in clonal organisms? A field test in the marine angiosperm Zostera marina. Mol Ecol 15:277-286

> Reusch TBH, Stam WT, Olsen JL (2000) A microsatellitebased estimation of clonal diversity and population subdivision in Zostera marina, a marine flowering plant. Mol Ecol 9:127-140

Reusch TBH, Ehlers A, Hammerli A, Worm B (2005) Ecosystem recovery after climatic extremes enhanced by genotypic diversity. Proc Natl Acad Sci USA 102:2826-2831

Ruckelshaus MH (1996) Estimation of genetic neighborhood parameters from pollen and seed dispersal in the marine angiosperm Zostera marina L. Evolution 50:856-864

- Ruckelshaus MH (1998) Spatial scale of genetic structure and an indirect estimate of gene flow in eelgrass, Zostera marina. Evolution 52:330-343

Ruggiero MV, Reusch TBH, Procaccini G (2005) Local genetic structure in a clonal dioecious angiosperm. Mol Ecol 14:957-967

Slatkin M (1987) Gene flow and the geographic structure of natural populations. Science 236:787-792

> Tack AJM, Roslin T (2011) The relative importance of hostplant genetic diversity in structuring the associated herbivore community. Ecology 92:1594-1604

> van Dijk JK, van Tussenbroek BI, Jimenez-Duran K, Marquez-Guzman GJ, Ouborg J (2009) High levels of gene flow and low population genetic structure related to high dispersal potential of a tropical marine angiosperm. Mar Ecol Prog Ser 390:67-77

Vekemans X, Hardy OJ (2004) New insights from fine-scale spatial genetic structure analyses in plant populations. Mol Ecol 13:921-935

Veliz D, Duchesne P, Bourget E, Bernatchez L (2006) Genetic evidence for kin aggregation in the intertidal acorn barnacle (Semibalanus balanoides). Mol Ecol 15:4193-4202

- Vellend M (2006) The consequences of genetic diversity in competitive communities. Ecology 87:304-311

Weir BS, Cockerham CC (1984) Estimating F-statistics for the analysis of population structure. Evolution 38: 1358-1370

- West SA, Pen I, Griffin AS (2002) Cooperation and competition between relatives. Science 296:72-75

Whitham TG, Bailey JK, Schweitzer JA, Shuster SM and others (2006) A framework for community and ecosystem genetics: from genes to ecosystems. Nat Rev Genet 7:510-523

Williams SL (2001) Reduced genetic diversity in eelgrass transplantations affects both population growth and individual fitness. Ecol Appl 11:1472-1488

Williams SL, Heck KL (2001) Seagrass community ecology. In: Bertness M, Gaines S, Hay M (eds) Marine community ecology. Sinauer Press, Sunderland, MA, p 317-337

Zhou HP, Chen J (2010) Spatial genetic structure in an understorey dioecious fig species: the roles of seed rain, seed and pollen-mediated gene flow, and local selection. J Ecol 98:1168-1177

Submitted: August 3, 2011; Accepted: October 10, 2011 Proofs received from author(s): January 30, 2012 